\title{
Nosocomial and non-nosocomial Clostridium difficile infections hospitalised patients in Belgium - compulsory surveillance data from 2008 to 2010
}

N Viseur (natacha.viseur@wiv-isp.be) ${ }^{1}, \mathbf{M}$ L Lambert ${ }^{1}$, M Delmée $^{2}$, J Van Broeck ${ }^{2}$, B Catry ${ }^{1}$

1. Public Health and Surveillance Department, Scientific Institute for Public Health, Brussels, Belgium

2. Microbiology Unit, Catholic University of Louvain, Brussels, Belgium

Viseur N, Lambert ML, Delmée M, Van Broeck J, Catry B. Nosocomial and non-nosocomial Clostridium difficile infections hospitalised patients in Belgium compulsory surveillance data from 2008 to 2010

Euro Surveill. 2011;16(43):pii=20000. Available online: http://www.eurosurveillance.org/ViewArticle.aspx?Articleld=20000

Surveillance of Clostridium difficile infection (CDI) is compulsory in Belgian hospitals. Our objectives were to compare incidence and case characteristics of nosocomial infections (Nc-CDI) with onset of diarrhoea more than two days after hospital admission, with non-nosocomial cases (Nnc-CDI). The database included inpatients from 2008 to 2010 . Of 8,351 cases reported by 150 hospitals, 3,102 (37\%) were classified as Nnc-CDI and 5,249 (63\%) as Nc-CDI. In 2010, the mean incidence per 1,000 admissions was 0.95 for Nc-CDI and 0.56 for Nnc-CDI. Both incidences were relatively stable over the three years, with a slight decrease in 2010 ( $p<0.01$ ). Onset of symptoms in NncCDI cases took place in the community (57.1\%), nursing homes $(14.2 \%)$ or hospitals $(17.5 \%)$; data for $11.2 \%$ were missing. Nnc-CDI cases were younger than Nc-CDI (median age 75 vs. 79 years, p<0.001), and more likely to be women ( $62 \%$ vs. $57 \%$, p $<0.001)$ and to have pseudomembranous colitis ( $5.3 \%$ vs. $1.6 \%$, p<0.001). In 2009, C. difficile ribotype 027 was found in 32 of 70 reporting hospitals compared with 19 of 69 in 2010 (p<0.03). Although our study population only included hospitalised patients, the results do not support the hypothesis of an increase in the incidence of severe community-associated CDI.

\section{Introduction}

Clostridium difficile infection (CDI) is the leading cause of diarrhoea in healthcare settings. In recent years, an increase in the incidence and the severity of nosocomial (Nc) or healthcare-associated CDI has been reported in Canada [1], the United States [2], and several European countries [3]. This rise has in part been explained by the emergence of a new virulent strain, PCR ribotype 027 [4], although in some countries, for instance Germany, an increase in CDI incidence had been described several years before the virulent strain 027 occurred [5].

In Belgium, CDI incidence and mortality more than doubled between 1998 and 2007 [6]. PCR ribotype 027 was identified for the first time in 2005 from a hospital outbreak [7]. In that context, a nation-wide prospective surveillance of CDI in hospitals was introduced by the Institute of Public Health (WIV-ISP) in 2006 which became compulsory in July 2007.

Although strains attributed to severe pathology are generally found in hospital inpatients, recent reports suggest that the occurrence and severity of CDI in the community is also increasing [8,9]. Moreover, CDI is increasingly recognised as a cause of diarrhoea in populations previously considered to be at low risk [10-12]. Recent reports have shown that CDI, including severe cases, can also occur in infants and children $[13,14]$, healthy young people living in the community, and peripartum women $[8,15]$.

In this article, using data from the compulsory surveillance of CDI in hospitals in Belgium, we compared incidence of Nc and non-nosocomial (Nnc) cases over the last three years (2008-2010) and compared the cases in terms of age, sex, and severity of the infection.

\section{Methods}

Prospective surveillance of CDI in hospitals in Belgium was introduced in July 2006 and became compulsory in July 2007 for all hospitals. Psychiatric and chronic care hospitals of less than 150 beds are statutory excluded, but their voluntary participation is encouraged. The full surveillance protocol [16] and the annual report of the surveillance [17] are available in Dutch and French at our dedicated website.

\section{Study design}

We analysed all CDI cases recorded in the hospitalbased surveillance for hospitals participating in the period from 1 January 2008 to 31 December 2010.

\section{Definitions}

Recent recommendations for the definition of CDI cases [18] were followed in the protocol. A CDI case 
was defined as a patient with symptoms of diarrhoea or toxic megacolon combined with a positive result of a laboratory assay and/or endoscopic or histopathologic evidence of pseudomembranous colitis. Participating hospitals were asked to apply this definition to all hospitalised patients recorded during the surveillance. Fulfilment of the definition was checked for each individual case by the WIV-ISP.

Cases were classified as Nc-CDI cases if onset of diarrhoea took place more than two days after admission to the reporting hospital. All other cases were classified as Nnc-CDI cases, and the place of onset of symptoms was recorded.

\section{Data analysis}

Mean annual incidence was calculated as the sum of CDI cases across all reporting hospitals in a given year divided by the sum of denominators (i.e. number of hospital-days or admissions). Incidences for Nc-cases are expressed by hospital-days and by admissions. For Nnc and total cases, the denominator of hospital-days is irrelevant, and incidences were calculated only by admissions.

The STATA 10.1SE (StataCorp. College Station, Texas, United States) statistical package was used for analysis.

\section{Ribotyping}

In the surveillance protocol, each hospital is asked to send five consecutive isolates from CDI patients to the national $C$. difficile reference laboratory every year. All strains are ribotyped by $P C R$, based on the comparison of patterns of PCR products of the 16S-23S rRNA intergenic spacer regions using primers described by

\section{TABLE 1}

Incidence of Clostridium difficile infection in hospitals in Belgium, 2008-2010 ( $\mathrm{n}=6,733)$

\begin{tabular}{|c|c|c|c|}
\hline Year & 2008 & 2009 & 2010 \\
\hline Number of hospitals & 107 & 107 & 91 \\
\hline \multicolumn{4}{|l|}{ Reported CDI } \\
\hline Number of total cases & 2,354 & 2,321 & 2,058 \\
\hline Proportion of nososomial cases ${ }^{a}$ & $63.3 \%$ & $61.4 \%$ & $63.3 \%$ \\
\hline \multicolumn{4}{|l|}{ Mean incidence of $C D I^{b}$} \\
\hline \multicolumn{4}{|l|}{ All cases } \\
\hline per 1,000 admissions & 1.87 & 1.82 & $1.52^{c}$ \\
\hline \multicolumn{4}{|l|}{ Nosocomial cases ${ }^{a}$} \\
\hline per 1,000 admissions & 1.18 & 1.12 & 0.95 \\
\hline per 10,000 hospital-days & 1.48 & 1.46 & 1.26 \\
\hline \multicolumn{4}{|l|}{ Non-nosocomial cases } \\
\hline per 1,000 admissions & 0.69 & 0.70 & 0.56 \\
\hline
\end{tabular}

CDI: Clostridium difficile infections.

a Symptom onset (diarrhoea) more than two days after admission to reporting hospital.

b Total cases across reporting hospitals/total denominators.

p<0.01, Pearson's chi-squared test: difference to 2008 incidence.
Barbut et al. [19]. The size of each peak was determined using GeneScan software or GeneMapper V.4 software (AB(Applied Biosystems).

\section{Results}

From 1 January 2008 to 31 December 2010, a total of 8,882 episodes of CDI were registered by 150 hospitals. We excluded 531 episodes (6\%), which did not meet the case-definition for CDI (e.g. symptoms of diarrhoea without a positive result of toxin detection). Descriptive data were analysed from a total of 8,351 CDI episodes from 7,646 patients. For our incidences analysis, only hospitals that contributed for an entire calendar year were selected, which left a total of 6,733 CDI episodes registered by 136 hospitals. Of these, 4,214 were defined as nosocomial.

\section{Incidences}

The mean annual incidence of CDI across hospitals that contributed surveillance data for an entire year in the study period is shown in Table 1 . The slightly decreasing incidence of $\mathrm{Nc}-\mathrm{CDI}$ over the three consecutive years and the large variability of incidences between hospitals are shown in Figure 1. Overall, the mean incidence of $C D I$ was $1.87,1.82$ and 1.52 per 1,000 admissions in 2008, 2009 and 2010 , respectively and $37 \%$ of CDI were considered to be Nnc-cases. Trends over time of incidences of Nc and Nnc-CDI evolved in parallel and seemed to be stable (Table 1).

Ribotyping data from the reference laboratory In 2010, C. difficile ribotype 027 was identified in 19 of 69 hospitals sending CDI stool samples for typing

\section{FIGURE 1}

Distribution of incidences of nosocomial Clostridium difficile infection per 10,000 hospital-days in Belgian hospitals, 2008-2010 (n=4,214)

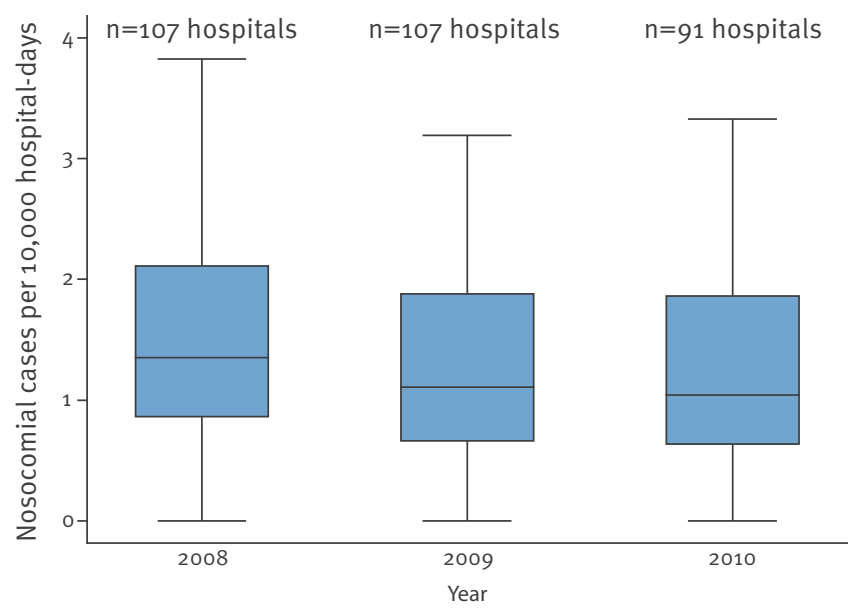

Boxes contain the middle $50 \%$ of the data; line in the box: median value; upper edge (hinge): 75 th percentile; lower edge (hinge): 25 th percentile; the range of the middle two quartiles is known as the inter-quartile range; the ends of the vertical lines (whiskers) indicate the minimum and maximum data values, unless outliers are present in which cases the whiskers extend to a maximum of 1.5 times the inter-quartile range.

Statistical outliers were excluded. 
(Table 2). This proportion was lower than previous years (28\% and $46 \%$ in 2010 and 2009, respectively; p<0.03).

\section{Characteristics of patients with} Clostridium difficile infection

The median age of the $7,646 \mathrm{CDI}$ patients that met the case definition was 78 years ( $\mathrm{P}_{25}$ - $\mathrm{P}_{75}$ : $64-85$ years), and $59 \%$ were female. Of the 8,351 episodes of CDI associated with these patients, 5,249 episodes (63\%) occurred more than two days after admission to the reporting hospital (Nc-CDI). In comparison with Nc-CDI patients, Nnc-CDI patients were younger (75 years for Nnc vs. 79 years for Nc cases, p<0.001 (Mann-Whitney test)) (Figure 2) and with a higher proportion of women (62\% for Nnc vs. $57 \%$ for Nc cases, p<0.001 (Pearson's chi-squared test)).

With regard to the severity of the infection, the proportion of pseudomembranous colitis among Nnc-CDI cases was higher (5.3\% for Nnc vs. $1.6 \%$ for Nc cases, p<0.001 (Pearson's chi-squared test)). In 2010, this proportion in Nnc-CDI cases was lower than in the previous years, although the difference was not statistically significant $(4.9 \%$ and $6.1 \%$ in 2010 and 2008 , respectively; $p=0.27$ (Pearson's chi-squared test)). For the 3,102 Nnc-CDI cases included in the study, onset of symptoms took place in the community $(n=1,761$, $57.1 \%)$, in a nursing home $(n=447,14.2 \%)$ or in the reporting or another hospital $(n=543,17.5 \%)$, while $11.2 \%(n=351)$ remained unclassified due to missing data.

\section{Discussion}

Data from the last three years showed a relatively stable incidence of CDI in Belgian hospitals, with a slight

\section{TABLE 2}

Riboptypes distribution among Clostridium difficile infections in Belgian hospitals, 2008-2010 ( $\mathrm{n}=1,663$ samples)

\begin{tabular}{|l|c|c|c|}
\hline Year & $\begin{array}{c}2008 \\
\text { Jan-Jun }\end{array}$ & $\begin{array}{c}2009 \\
\text { Jan-Jun }\end{array}$ & $\begin{array}{c}2010 \\
\text { Jan-Jun }\end{array}$ \\
\hline $\begin{array}{l}\text { Number of hospitals who sent CDI stool } \\
\text { samples for typing }\end{array}$ & 51 & 70 & 69 \\
\hline Hospitals with ribotype 027 & 28 & 32 & 19 \\
\hline Number & $55 \%$ & $46 \%$ & $28 \%^{\text {a }}$ \\
\hline Proportion & 10 & 25 & 23 \\
\hline Hospitals with ribotype 014 & $20 \%$ & $36 \%$ & $33 \%$ \\
\hline Number & 19 & 8 & 16 \\
\hline Proportion & $37 \%$ & $11 \%$ & $23 \%$ \\
\hline Hospitals with ribotype 078 & & \\
\hline Number & & \\
\hline Proportion & & \\
\hline
\end{tabular}

CDI: Clostridium difficile infections.

a pro.03, Pearson's chi-squared test: difference to 2009 proportion. decrease in 2010. These findings do not support the hypothesis $[8,9]$ of an increase in the incidence of severe (e.g. leading to hospitalisation) communityassociated CDI. In Belgium, $75 \%$ of deaths associated with a CDI diagnosis take place in a hospital [6]. Therefore we consider our assessment of the severity of community-associated cases using only hospitalised cases a fair approximation of the reality. The large variability of incidences between hospitals seems unlikely to be attributed only to case mix variation. Health services research has led to the conclusion that unexplained variation in a number of important clinical areas is a very significant issue, and that there could be huge improvements if the poorest performers could match the best [20].

If the variation in $C$. difficile rates is not explained by case mix, then it might be due to differences in prevention practices, which would indicate that there is a potential for improved prevention. But more research is needed to test this hypothesis in the field of healthcare-associated infections. The proportion of hospitals where ribotype 027 was found decreased in 2010 , but a limitation of these data is that only 70 hospitals sent samples for typing, against 110 who contributed to the epidemiological data.

The incidence of all CDI in Belgium was comparable with the incidences of 1.1 per 1,000 admissions reported in France in 2009 [21] and 1.8 per 1,000 admissions reported in the Netherlands in 2008 [22], although the data in these countries are collected voluntarily and thus not as representative compared with the compulsory Belgian surveillance. It was lower than in Germany (1.4 vs 4.6/1,000 admissions in 2007) [23]. Unlike in Belgium, participation in the national surveillance in

\section{FIGURE 2}

Age distribution of patients with Clostridium difficile infections in Belgian hospitals, 2008-2010 ( $n=7,646$ patients)

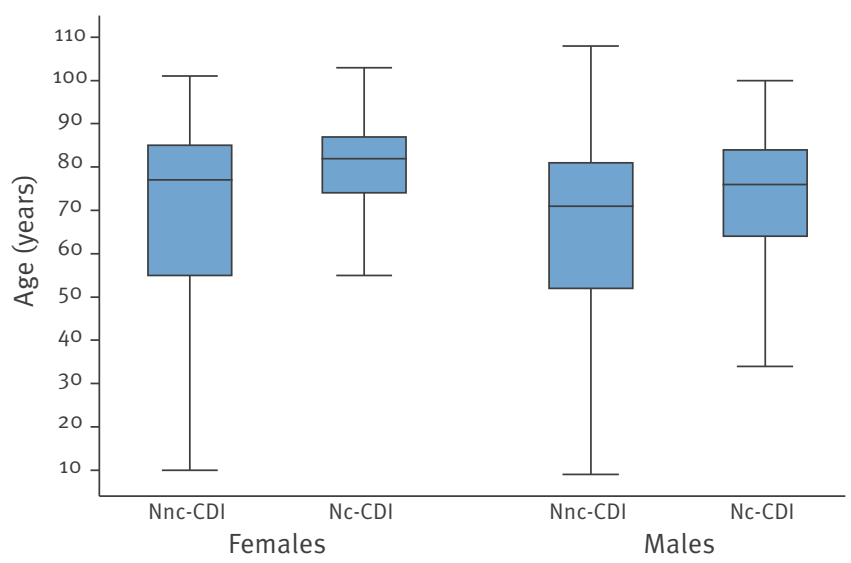

CDI: Clostridium difficile infections; Nc: nosocomial; Nnc: non-nosocomial.

Statistical outliers were excluded. 
Germany is voluntary and a bias towards a participation of hospitals with higher incidence might have been involved.

The incidence of Nc-CDI in Belgium was lower than that reported in a European-wide hospital-based survey specific for CDI, performed in 2008 (97 hospitals in 34 European countries) [24]. Importantly, the incidence of Nc-CDI in the three Belgian hospitals that participated in that survey (2.8/10,000 hospital-days) was higher than the incidence here reported in our nation-wide surveillance of 98 hospitals $(1.5 / 10,000$ hospital-days in 2008), which suggests that, at least for Belgium, the survey overestimated the incidence numbers due to the limit number of hospitals included. In England [25] and in Québec [26], Nc-CDI surveillance is also compulsory. The mean incidence of Nc-CDI in these countries in the period from April 2009 to March 2010 was higher (3.6 and 6.3/10.000 hospital-days, respectively) than in Belgium (1.3/10.000 hospital-days in 2010).

The strengths of the Belgian surveillance are the wide coverage of hospital data and the possibility for hospitals to follow their incidence in a secured webbased follow-up system in real time, thus they receive rapid feedback after recording, which can be used to make local improvements. Indeed, comparable data, i.e. data from a representative sample of hospitals and recent data, are scarce in the literature. A limitation of our system is that the data do not allow us to provide incidence per inhabitants and to estimate a cross-transmission at national level.. By definition, our surveillance only includes the more severe (hospitalised) community-associated CDI.

\section{Conclusion}

The incidence of all CDI in hospitalised patients from Belgium was stable over the period 2008 to 2010, although a slight decrease was observed in 2010. The incidence in Belgium is comparable with the incidence reported in surrounding countries like France and the Netherlands. Although our study population only included hospitalised patients, the results do not support the hypothesis $[8,9]$ of an increase in the incidence of severe community-associated CDI. The large variability of incidence between the hospitals in our study suggests that a proportion of these infections, although hard to quantify, could be prevented by improving classical infection control methods. Current CDI surveillance in Belgium is a useful and valid tool to monitor trends in incidence and severity of cases in Belgian hospitals.

\section{References}

1. Pepin J, Valiquette L, Alary ME, Villemure P, Pelletier A, Forget $\mathrm{K}$, et al. Clostridium difficile-associated diarrhea in a region of Quebec from 1991 to 2003: a changing pattern of disease severity. CMAJ. 2004;171(5):466-72.

2. Zilberberg MD, Shorr AF, Kollef $M H$. Increase in adult Clostridium difficile-related hospitalizations and casefatality rate, United States, 2000-2005. Emerg Infect Dis. 2008;14(6):929-31.
3. Kuijper EJ, Barbut F, Brazier JS, Kleinkauf N, Eckmanns T, Lambert ML,et al. Update of Clostridium difficile infection due to PCR ribotype 027 in Europe, 2008. Euro Surveill. 2008;13(31):pii=18942. Available from: http://www. eurosurveillance.org/ViewArticle.aspx?Articleld=18942

4. Warny M, Pepin J, Fang A, Killgore G, Thompson A, Brazier J, et al. Toxin production by an emerging strain of Clostridium difficile associated with outbreaks of severe disease in North America and Europe. Lancet. 2005;366(9491):1079-84.

5. Zaiß NH, Witte W, Nübel U. Fluoroquinolone resistance and Clostridium difficile, Germany. Emerg Infect Dis. 2010;16(4):675-7.

6. Gutierrez I, Lambert ML. Trends in mortality and morbidity related to Clostridium difficile infections, Belgium 1998-2007. Brussels: Scientific Institute for Public Health; April 2010. ISSN : D/2010/2505/18. Available from: http://www.nsih.be/ download/CDIF/CDI_trends_mortality_morbidity_final_report_ June_2010.pdf

7. Joseph R, Demeyer D, Vanrenterghem D, van den Berg R, Kuijper E, Delmee M. First isolation of Clostridium difficile PCR ribotype 027, toxinotype III in Belgium. Euro Surveill. 2005;10 (42): pii=2815. Available from: http://www.eurosurveillance. org/ViewArticle. aspx?Articleld $=2815$

8. Centers for Disease Control and Prevention (CDC). Severe Clostridium difficile-asssociated disease in populations previously at low risk -- four states, 2005. MMWR Morb Mortal Wkly Rep. 2005;54(47):1201-5.

9. Centers for Disease Control and Prevention (CDC). Surveillance for community-associated Clostridium difficile--Connecticut, 2006. MMWR Morb Mortal Wkly Rep. 2008;57(13):340-3.

10. Kutty PK, Woods CW, Sena AC, Benoit SR, Naggie S, Frederick J, et al. Risk factors for and estimated incidence of communityassociated Clostridium difficile infection, North Carolina, USA. Emerg Infect Dis. 2010;16(2):197-204.

11. McFarland LV, Clarridge JE, Beneda HW, Raugi GJ. Fluoroquinolone use and risk factors for Clostridium difficileassociated disease within a veterans administration health care system. Clin Infect Dis. 2007;45(9):1141-51.

12. Wilcox MH, Mooney L, Bendall R, Settle CD, Fawley WN. A casecontrol study of community-associated Clostridium difficile infection. J Antimicrob Chemother. 2008;62(2):388-96.

13. Zilberberg MD, Shorr AF, Kollef MH. Increase in Clostridium difficile-related hospitalizations among infants in the United States, 2000-2005. Pediatr Infect Dis J. 2008;27(12):1111-13.

14. Kim J, Smathers SA, Prasad P, Leckerman KH, Coffin S, Zaoutis T. Epidemiological Features of Clostridium difficile-Associated Disease Among Inpatients at Children's Hospitals in the United States, 2001-2006. Pediatrics. 2008;122(6):1266-70.

15. Rouphael NG, O’Donnell JA, Bhatnagar J, Lewis F, Polgreen PM, Beekmann S, et al. Clostridium difficile-associated diarrhea: an emerging threat to pregnant women. Am J Obstet Gynecol. 2008;198(6):635-6.

16. Scientific Institute for Public Health (ISP). Surveillance des infections à Clostridium difficile. Protocole. [Surveillance of Clostridium difficile infections. Protocol]. Version 4.0. Brussels: ISP; 2010. French. Available from: http://www.nsih. be/surv_cdif/download_fr.asp

17. Viseur N, Lambert ML. Epidémiologie des infections à Clostridium difficile en Belgique; rapport 2011. [Epidemiology of Clostidium difficile infections in Belgium ; report 2011]. Brussels: Scienific Institute for Public Health; 2011. ISSN version online: $2034-4562$. French. Available from:http://www. nsih.be/download/CDIF/CDIF-AR-2011-FR.pdf

18. Bauer MP, Kuijper EJ, van Dissel JT; European Society of Clinical Microbiology and Infectious Diseases. European Society of Clinical Microbiology and Infectious Diseases (ESCMID): treatment guidance document for Clostridium difficile infection (CDI). Clin Microbiol Infect. 2009;15(12):1067-79.

19. Barbut F, Mario N, Delmée M, Gozlan J, Petit JC. Genomic fingerprinting of Clostridium difficile isolates by using a random amplified polymorphic DNA (RAPD) assay. FEMS Microbiol Lett. 1993;114(2):161-6.

20. The NHS Confederation. Variation in healthcare: does it matter and can anything be done? London: NHS Confederation; 2004. Available from: http://www.nhsconfed.org/Publications/ Documents/Variation\%20in\%2ohealthcare.pdf

21. Coignard B, Eckert C, Rahib D, Hébert M, Boussat S, Jarno P, et al. Caractéristiques épidémiologiques et microbiologiques des infections à Clostridium difficile en France: résultats de l'étude ICD-RAISIN 2009. [Epidemiological and microbiological characteristics of Clostridium difficile infections in France: reults of the ICD-RAISIN 2009 study]. Powerpoint presentation. XXIth congress of the de la SFHH. 3 June 2010; Bordeaux, France. French. Available from: http://www.cleanis.fr/docs/ news/fr/icd-en-france-en-2009_127840418738166800.pdf 
22. Hensgens MP, Goorhuis A, Notermans DW, van Benthem $\mathrm{BH}$, Kuijper EJ. Decrease of hypervirulent Clostridium difficile PCR ribotype 027 in the Netherlands. Euro Surveill. 2009;14(45): pii=19402. Available from: http://www. eurosurveillance.org/ViewArticle.aspx?Articleld=19402

23. Gastmeier P, Weitzel-Kage D, Behnke M, Eckmanns T. Surveillance of Clostridium difficile-associated diarrhoea with the German nosocomial infection surveillance system KISS (CDAD-KISS). Int J Antimicrob Agents. 2009;33 Suppl 1:S19-S23.

24. Bauer MP, Notermans DW, van Benthem BH, Brazier JS, Wilcox $\mathrm{MH}$, Rupnik M, et al. Clostridium difficile infection in Europe: a hospital-based survey. Lancet. 2011;377(9759):63-73.

25. Health Protection Agency (HPA). Results of the mandatory Clostridium difficile reporting scheme by acute Trust in UK (2007-2010). London: HPA. [Accessed June 2011]. Available from: http://www.hpa.org.uk/web/HPAweb\&HPAwebStandard/ HPAweb_C/1195733750761

26. Surveillance data on Clostridium difficile Infection in Québec hospitals. ISBN no: 2-550-45949-0. Québec: Ministère de la Santé et des Services sociaux (MSSS). [Accessed June 2011]. French. Available from: http://msssa4.msss.gouv.qc.ca/en/ document/publication.nsf/fb143c75eoc27b69852566aaoo64b 01c/gee11991af5fce358525753c00650c88?OpenDocument 